\title{
It's the Weather: Quantifying the Impact of Weather on Retail Sales
}

\author{
Natalie Rose $^{1}$ D $\cdot$ Les Dolega $^{1}$ (D)
}

Received: 1 June 2020 / Accepted: 10 May 2021 /Published online: 25 August 2021

(C) The Author(s) 2021

\begin{abstract}
The weather is considered as an influential factor on consumer purchasing behaviours and plays a significant role in many aspects of retail sector decision making. As a result, better understanding of the magnitude and nature of the influence of variable UK weather conditions can be beneficial to many retailers and other stakeholders. This study addresses the dearth of research in this area by quantifying the relationship between different weather conditions and trading outcomes. By employing comprehensive daily sales data for a major high street retailer with over 2000 stores across England and adopting a random forest methodology, the study quantifies the influence of various weather conditions on daily retail sales. Results indicate that weather impact is greatest in the summer and spring months and that wind is consistently found to be the most influential weather condition. The top five most weather-dependent categories cover a range of different product types, with health foods emerging as the most susceptible to the weather. Also, sales from out-of-town stores show a far more complex relationship with the weather than those from traditional high street stores with the regions London and the South East experiencing the greatest levels of influence. Various implications of these findings for retail stakeholders are discussed and the scope for further research outlined.
\end{abstract}

Keywords Retail $\cdot$ UK weather $\cdot$ High street retailers $\cdot$ Machine learning

Natalie Rose

n.rose@liverpool.ac.uk

Les Dolega

ldolega@liverpool.ac.uk

1 Department of Geography and Planning, University of Liverpool, 74 Bedford Street S, Liverpool L69 7ZT, UK 


\section{Introduction}

Retail is arguably one of the most important economic sectors in the UK (CocaStefaniak, 2013), contributing approximately 5\% of total GVA in 2019 (Retail Economics, 2020), and providing employment for approximately 3.1 million people (British Retail Consortium, 2020). It is also a landscape that is highly dynamic and has faced some significant challenges in recent years. In response to these challenges, retailers often revaluate their existing business models, store portfolios and are under increasing pressure to improve efficiency in many areas of the business, such as stock management and pricing strategies. As such, better understanding the key influences and drivers of sales is incredibly important for retailers so they can continuously evaluate evolving consumer purchase behaviour and stay competitive. In addition to more obvious factors, such as consumer confidence (Allenby et al., 2012; Tartaglione et al., 2019), spending trends (Jones \& Livingstone, 2017), technology or catchment geodemographics (Singleton et al., 2015), it is increasingly important to incorporate weather into these sales forecasts (Sivillo \& Reilly, 2004; Beheshti-Kashi et al., 2014).

It has been long acknowledged that weather is an influential factor in many aspects of decision making in the retail sector, the scale of which is summarised as impacting both directly and indirectly at all spatial and temporal scales (Lazo et al., 2011). Weather has a huge role in everyday life (Sivillo \& Reilly, 2004) and from a consumer perspective, it often influences a decision of whether to make a shopping outing or a purchase a particular product. In the UK, where the weather is characteristically variable (Slingo et al., 2014) and susceptible to a range of extremes (Hanna et al., 2017), it is a topic frequently brought to public attention by the media. This is particularly apparent in regard to short-term changes in retail sales that correspond with weather extremes such as heatwaves, storms or cold spells (e.g. Chu, 2018; Inman, 2018). With projections of nationwide warming and increased variability of other conditions (Murphy et al., 2010), as well as more frequent weather extremes (Herrera et al., 2016; Kantamaneni \& Du, 2017), it is likely that weather is only going to have a greater impact on the retail sector in years to come. Although impossible to predict what these impacts may be, a greater understanding of the current level of influence can help inform and prepare stakeholders for future change. Despite being a subject that regularly attracts media attention, there is little academic research pertaining to this issue, not only for extremes, but weather in general. As such, providing robust empirical evidence that quantifies the impact is viewed as novel and beneficial to a number of stakeholders. This study aims to quantify the relationship between various weather conditions and daily retail sales. There are three key objectives of this research project: first, to quantify the overall level of influence that weather has on total sales; second, to identify which product types can be considered to be the most weather dependent; and third, to investigate whether the trends in sales show any spatial variation, both local and regional.

The paper proceeds in the following way: Firstly, the existing literature in this area will be critically reviewed and the gap for this research identified. The 
methodology will then introduce the data and methods used and outline the final models. Results will be presented in four parts, covering the influence of weather on total sales, individual product categories and the local and regional spatial variations in influence, respectively. In each case, results will be discussed using existing literature. Ultimately, key results and findings will be summarised, and the limitations and implications of this study considered.

\section{Literature Review}

\section{Factors Influencing Retail Performance}

In recent years retail landscapes have been experiencing turbulent changes that have challenged many brick and mortar retailers and, as a result, traditional UK high streets (Parker et al., 2015; Theodoridis et al., 2017). These changes have been commonly attributed to a range of factors, including economic uncertainties (Grimsey, 2018; Portas, 2011; Wrigley \& Lambiri, 2015); 'slow burns' such as pressures on the high street from the growth of out-of-town centres (Lang, 2012; Parker et al., 2015) and e-commerce (Zhang et al., 2016; Dolega \& Celinska-Janowicz, 2015); or keeping up with changing consumer purchase behaviour (Howard, 2007; Pendall et al., 2010). In addition, there are the less commonly considered detrimental effects of apathetic landlords (Portas, 2011) and retail centre fragmentation across key transport routes (Parker et al., 2014). As a result, these numerous convoluting factors make understanding retail purchasing behaviours and the decision-making process of consumers profoundly complex. In some cases, the response of the retail sector is somewhat predictable e.g. declined performance in the wake of the economic downtown, whilst others are unforeseen e.g. political uncertainty weakening financial value (Grimsey, 2018). Unforeseen impacts may also include extreme weather events or global health pandemics. Research shows that retail sales are influenced by various economic measures, such as the consumer price index (CPI), disposable income, consumer confidence and unemployment levels (Allenby et al., 2012; Grimsey, 2018; Tartaglione et al., 2019).

In addition to these structural elements, the functional characteristics of stores, such as the size and location, have been found to be crucial "micro" factors in predicting retail performance (Lusch et al., 2015). Store size, and the subsequent implications for merchandise assortment, are commonly used as proxy for retail destination attractiveness in various store location modelling approaches, such as spatial interaction models, and are key determinants for predicting store revenue (Sturley et al., 2017). Smaller stores, typically holding a standard range of necessity items are likely to fulfil different shopping purposes than larger stores that branch out into more luxury goods. Moreover, variations in product offering have been found to influence business resilience and sensitivity to economic or environmental factors (Meitzer, 2016; Astbury \& Thurstain-Goodwin, 2014). Similarly, store location has been found be a key determinant of retail performance as different shopping destinations provide distinct offerings in terms of their facilities and characteristics. Out-oftown centres in particular have been found to benefit over town centres due to their 
decentralised location enabling greater accessibility by car, offering free car parking and subsequently greater ease of large goods collection (Jones \& Livingstone, 2017). Often consumers with purposeful shopping intentions are more likely to visit out-of-town centres (Alzubaidi et al., 1997), whilst trips to town centres were found to serve a greater variety of intentions. For instance, consumers are more likely to travel longer distances to out-of-town centres for quick and efficient purchases ('run shopping'), whereas high streets are used more for 'fun shopping' purposes (Gorter et al., 2003). Although there is some evidence that in general, consumers use each type of centre for different purposes (Gorter et al., 2003), often the choice of a shopping destination is related to the prevailing weather conditions (Arunraj \& Ahrens, 2016).

Importantly, there is an inherent seasonality in the retail sector (Aye et al., 2015; Fildes et al., 2019), which occurs both in overall sales volumes (e.g. Starr McCleur, 2000) and individual product sales (e.g. Bahng \& Kincade, 2012). Jang (2004) attributes this seasonality to two main factors, the natural climatic seasons and their corresponding weather conditions, and institutional seasons reflecting social norms such as religious or school holidays. In the UK, a key seasonal trend is the increase in retail activity over the Christmas period with December total retail spending typically up 45-55\% on the rest of the year (ONS, 2013). There is also a growing body of literature examining the impact of tourism on retail activities in British tourist hotspots (e.g. Newing et al., 2018). With respect to the types of products sold, fashion retail (Xia \& Wong, 2014; Martinez-de-Albeniz \& Belkaid, 2019) and food and drink retail (Ramanathan \& Muyldermans, 2010; Mirasgedis et al., 2014) are prominent examples of sectors that are highly seasonal.

Although there is a general awareness of seasonality in retail sales, there is often lack of understanding of the direct relationships between weather and sales (Stulec et al., 2019). Typically, weather conditions influence a consumer's decision-making process, from what they buy to when they buy it and where they buy it from. These influences then have knock-on effects for retailers and other stakeholders, such as stock management and staffing. This is particularly important for the UK that experiences characteristically variable and unpredictable weather (Slingo et al., 2014; Hanna et al., 2017). Different regions of the UK experience varied weather profiles with south east England experiencing the warmest and driest conditions whilst the west experiences more wind and rain. Additionally, arctic air from the north can bring prominent cold spells across the UK, particularly in the autumn and winter months. Furthermore, due to the growing impacts of global climatic change, there is significant uncertainty with regards to future weather conditions and the impacts these will bring on consumption patterns. Murphy et al. (2010) found that warming is likely to happen all across the UK, while other weather conditions are predicted to become increasingly variable with a prominent north-south gradient. There is also an increasing likelihood of extreme weather in the UK including super storms (Kantamaneni \& Du, 2017) and flooding (Thompson et al., 2017), as well as substantial increases in heatwave intensity and frequency (Herrera et al., 2016). As a result, it is highly likely that the impact on retail sales will be different, and perhaps greater, than in other places such as mainland Europe or the US, yet there is little research specifically investigating UK retail. 


\section{How Does the Weather Influence Retailing?}

Daily weather conditions, and fluctuations in weather conditions, are known to be key influences on many economic sectors, estimated to affect as much as 35\% of GDP in industrialised countries (Parnaudeau \& Bertrand, 2018), and can determine the level of success or failure of a business (Ellithorpe \& Putnam, 2000). As a result, weather is undisputedly an important factor that retailers need to be aware of, particularly when forecasting sales or planning merchandising seasons, for example. Varying and unseasonal weather conditions can create issues of over- or understocking for retailers with subsequent impacts such as shelf-space management, losses as a result of price reductions, or wastage (Agnew \& Thornes, 1995). Some companies, such as Starbucks and Budweiser, have found benefit in implementing weather forecasts into marketing or promotional activities (Bradlow et al., 2017) and others have been known to deliberately promote 'feel-good' products during periods of unfavourable weather (Grewal et al., 2017). However, the impact that weather has on sales can be difficult to monitor, and the variability of factors influencing product demand can create many difficult issues for retailers to contend with (Arunraj \& Ahrens, 2016), especially when it is not just seasonal variations that are to be considered but also the deviations from seasonal conditions (Starr-McCleur, 2000).

In a broad sense, the research relating to weather impact on retail sales sits within a large bank of literature investigating various factors influencing retail sales however, research investigating the impact of weather is relatively sparse. According to Steele (1951), there are considered to be four key effects on retail sales:

(1) weather can create uncomfortable conditions that may dissuade consumers from shopping;

(2) weather can create conditions which may physically prevent shopping behaviours;

(3) weather can induce psychological effects that change consumer habits;

(4) the desirability of certain categories of product may be affected due to prevailing weather conditions.

Since, Steele's theories have influenced and formed the basis for many academic studies regarding the impact of weather on various aspects of the retail sector and can be linked to other theories surrounding the impacts that weather can have on the retail sector, summarised by Stulec (2013). They cover both the nature and the magnitude of these impacts including: (i) the Purchase Timing Theory, where daily sales may be affected by certain weather conditions but there is no overall impact; (ii) the Permanent Impact Theory claiming that prevailing weather conditions influence consumers to buy products impulsively and (iii) the Weather/Consumption Theory claiming that weather has a significant effect on the retail economy as a whole.

These studies cover a range of different aspects of retail, some focussing on retail economies, others on aggregate sales across a store or individual sales of a particular product. In the UK media, weather is frequently cited for causing short-term changes in retail sales, both favourably and detrimentally. A recent example of this is the 
reduced post-Christmas sales that were widely attributed to the poor weather conditions over the Christmas period acting as a deterrent for shoppers (Wood, 2019). In instances such as this, attributions are often made at purely observational level with little analysis undertaken to support quick conclusions made by stakeholders. From an empirical research perspective, the level and the nature of influence that weather has on retail sales has been the subject of a number of academic and commercial studies over the last few decades. These allow a deeper analysis of weather influence, amongst other factors, on sales to deepen understanding of a rapidly changing retail environment.

\section{Weather Conditions and Retail Sales}

The impact of weather on retail sales and consumer spending has been acknowledged and studied for some time (Bradlow et al., 2017) and in various contexts. For instance, Subak et al. (2000), when studying the performance of the UK retail sector as a whole, found that temperature had a greater impact than the amount of sunshine and that rainfall had the least association. However, other studies undertaken in this area focus predominantly on one particular store or use store case studies. Since seminal research in the 1950s, there have been several examples of empirical analysis undertaken on daily aggregated sales and the influence that different weather conditions can have. In a study of US department store sales, Steele (1951) found that weather variables could account for up to $42 \%$ of the variation seen in sales and that, with the exception of the presence of sunshine, all weather conditions presented a negative relationship with sales. Other research showed that the occurrence of rain caused a significant decrease on department store sales in New York (Linden, 1959) and concluded that all temperature, snow fall, sunlight and humidity presented a significant relationship with daily aggregated sales of a tea retailer (Murray et al., 2010). The temperature was also found by Ramanathan and Muyldermans (2010) to be a significant demand factor for bottles of soft drink in the UK, showing a positive association with sales. With respect to fashion retail, a study by Bahng and Kincade (2012) found that sales in South Korea were highly susceptible to temperature deviations and snowfall but that rain had no significant impact. Similarly, in France, unseasonal temperatures in spring and autumn were found to have a greater influence on fashion retail sales (Bertrand et al., 2015) and two German studies found that rainfall and snow both had a significant impact on food sales (Arunraj \& Ahrens, 2016) reporting a $4.1 \%$ increase in variance explained when weather variables were inputted into the daily sales model (Badorf \& Hoberg, 2020), repectively.

In some cases, studies have gone further than daily aggregates and have looked at the varying levels of impact weather variables can have on different product types. Agnew and Thornes (1995) focussed on the weather sensitivity of UK supermarket products and identified which products' sales increased and decreased the most with a decrease in temperature or sun hours. Porridge oats and shower gels were found to have the highest percentage increase and decrease, respectively. Furthermore, Mirasgedis et al. (2014) found that in Greece maximum temperature gave a strong 
positive association with the sales of each of the different soft drink products and that humidity showed a negative association with juice sales.

Finally, the impact of weather on other factors likely to impact retail sales such as footfall - a factor widely proven to be a key influence on sales - has also been examined (e.g. Graham, 2017; Makkar, 2020). A study analysing the impact of weather conditions on pedestrian counts in New Zealand, found that the 'most tangible' variables of temperature and rainfall show the strongest associations, both negative in nature (Parsons, 2001). Similarly, other studies showed that colder temperatures and high precipitation tended to dissuade pedestrians from frequenting US shopping districts (Aultman-Hall et al., 2009; Attaset et al., 2010). In addition, the impact of weather conditions on consumer mood and the subsequent influences on spending behaviours was investigated, finding that increasing sunlight exposure tends to reduce negative affect and consequently increase consumer spending (Murray et al., 2010).

\section{Spatial Variations in Weather Influence}

When investigating the impact of weather conditions on retail sales, various spatial scales need to be considered. Amongst local scale variables examined by researchers, the location of a store, whether it be in a high street or out-of-town setting, and the facilities offered in each case can have a significant impact on visit purpose or the types of products purchased. Research by Dellaert et al. (2008) shows that weather conditions are one of the top considerations for Dutch consumers when making shopping trip decisions. According to Padilla et al. (2017), the first decentralised and indoor mall was designed in the US in 1956 specifically to protect consumers from outdoor weather conditions. This acts as a contrast to high street retail offerings, which are often more spread out, with detached parking facilities and no cover between shops (Badorf \& Hoberg, 2020). Furthermore, all of these traits are likely to directly influence customer attainability in various ways due to weather conditions. This impact was identified by Arunraj and Ahrens (2016) who studied two food stores in Germany, one located in the town centre and one out-of-town and found varying levels of weather impact on the sales of each store. With respect to footfall, rainfall was found to be the main weather driver of variance across Europe leading to a $7.4 \%$ reduction in high street stores, but a $5.2 \%$ increase in out-of-town centres (Martinez-de-Albeniz \& Belkaid, 2019).

Despite existing research being sparse, the importance of regional differences in weather impact on retail sales was acknowledged by Agnew and Thornes (1995) who state that incorporating this into analysis could provide a more comprehensive evaluation of weather sensitivities. A US study revealed that regional variables consistently show significant and strong associations with the sales of groceries (Divakar et al., 2005). Typically, many studies are unable to consider regional differences due to the limitations of small study areas (e.g. Arunraj \& Ahrens, 2016) or the focus on one individual store (e.g. Murray et al., 2010). As a result, this is a major gap in the literature that needs addressing. The impact and nature of spatially varying associations between weather and retail is rarely explicitly studied. Both of these 
spatial factors will be directly considered and analysed in this study to gain a clearer understanding of what influence they have when it comes to the impact of weather on sales.

\section{Methodology}

In order to meet the objectives of this paper, we adopt a quantitative approach to investigate the level of influence that various weather conditions have on sales of individual items and explore the nature of these associations. By combining both extensive retail and weather datasets, it will provide empirical analysis of the magnitude and the nature of impact that weather can have on both daily aggregate item sales and sales stratified by product category. The adopted approach involves using data science, in particular machine learning techniques that are adept for handling data such as this to model the impacts. In this section we outline the data being used, the methodological approach and the development of the models being used to undertake this analysis.

\section{Sales Data}

The sales data used in this research was provided by a major high street retailer in the UK and obtained through the Consumer Data Research Centre (CDRC). This data offers extensive coverage of in-store sales, with more than 1.3 billion items sold across 2043 stores in England between April 2012 and Mar 2014, inclusive. In addition to being a UK high street staple, the retailer has stores in locations spanning out-of-town retail parks, shopping centres and transport hubs, such as airports and train stations. Furthermore, the store portfolio consists of a variety of sizes and subsequent formats from small convenience outlets to large flagship stores. The data consists of all individual item transactions during this study period including the price of the product; the date on which the transaction took place; the store in which the product was purchased; and the pre-defined product category in which it falls into. As product prices may be subject to fluctuation and the data does not provide information on any promotional activities, individual item sales were used in this analysis rather than the sales values. It must be noted, however, that the influence of sales promotions, for example multibuy offers, on the products consumers buy cannot be accounted for in this instance. At store level, information on store characteristics and location attributes were also provided.

The process of data preparation for analysis involved aggregation of all item sales by date and store, and then by product category to enable both total daily sales and individual product sales to be examined. Store level attributes were then added, including store format (based on the retailer's own classification) and store type (e.g. high street, transport hub, out-of-town centre). Any non-distinct product categories that represented either a mix of different services or were defined as 'other' categories were removed to leave 28 clearly defined product categories. In order to maintain consistency across different store types and varying opening hours on public 
holidays, all public holiday sales were removed. Similarly, days on which the retailer held an annual promotion were removed, so that the sales of products included in the promotion did not skew overall sales. After processing the data, there were approximately 1.24 billion item sales in total ready to be used for analysis, at a $94.7 \%$ retention rate. Finally, based on the findings of the literature review, monthly national employment rates and Consumer Price Index (CPI) values, obtained from the Office of National Statistics (ONS), were also added.

\section{Weather Data}

In order to compare sales with weather conditions, the Climate, Hydrological and Ecological research Support System (CHESS) meteorological data set was procured through the Centre for Ecology \& Hydrology (CEH) (Robinson et al., 2017). This data is publicly available and provides $1 \mathrm{~km}$ gridded daily averages that also take the impact of the topography across Great Britain into account. For the purpose of this analysis, the variables collected were the near surface air temperature $(1.2 \mathrm{~m})$; precipitation, based on the $\mathrm{CEH}$ : gridded estimates of areal rainfall dataset; the near surface wind speed $(10 \mathrm{~m})$; and the near-surface specific humidity $(1.2 \mathrm{~m})$. The gridded data for each variable was processed and re-formatted to provide daily averages for each LSOA across England, with missing values that fell outside of the raster layer being computed using the medians from connected neighbouring LSOA polygons. Once at LSOA level, these weather attributes were appended to the sales data based on the LSOA in which the store fell.

\section{Methodological Approach}

This paper uses random forest modelling, a supervised machine learning technique, to predict the number of items sold and quantify the level of influence that various weather variables have when added into the model. An example of tree-based regression, random forests combine a number of trees, each grown using a bootstrap sample of data and with a random selection of features from the model to split each node (Breiman, 2001). Key characteristics of random forests include the ability to combine both categorical and continuous variables; a resilience to outliers or noise in the data; and the converging nature of errors meaning there is less propensity for the model to overfit (Breiman, 2001). Random forest has been shown to outperform the multiple linear (generalised linear) regression models in situations where relationships between predictor variables and the outcome variable under investigation are nonlinear and complex, or situations where this nonlinear relationship is difficult to parameterise (Jeong et al., 2016). Additionally, random forest models produce accurate results out-of-the-bag (Davies et al., 2018) making them quick and easy to use, particularly when working with data of this size and complexity. The models in this analysis were constructed using the ranger package in R (Wright \& Ziegler, 2017). ranger was designed specifically as a fast implementation of the regular random forest algorithm and is particularly suited to data with a high level of dimensionality (Wright, 2020), making it the most efficient package for the dataset 
explored in this study. Furthermore, ranger allows more flexibility, e.g. not restricting the number of factors that can be processed for categorical variables that are included in the model (Wright \& Ziegler, 2017).

The aim of this analysis is more on understanding the influences of weather conditions on item sales rather than prediction or forecasting. Such inferences can be achieved and easily visualised by using partial dependence plots (PDPs). PDPs graph the nature of the relationship between the outcome variable and individual explanatory variables, enabling the results of a random forest to be more interpretable and less of a 'black box' method (Greenwell, 2017). The R package $p d p$ (Greenwell, 2017) was used to create these plots.

\section{Model Development}

For the purpose of this analysis, two random forest models were devised: the first, a control model; the second adding in the four weather condition attributes. As a result of the literature review findings, variables representing store characteristics, economic factors and temporal attributes were all used in the control model as key factors that influence sales. Characteristics include the type and format of the store as well as individual ID to account for store-specific sales signatures; the economic factors are monthly CPI and employment rate; and the temporal attributes indicating the day of week and day of year in which the sale took place., It is presumed that these factors, though not a comprehensive list of a large range of factors influencing sales, will explain the majority of the variation in the examined item sales. In a method similar to that used by Knoeferle et al. (2017), the level of weather dependence was determined using the change in $\mathrm{r}^{2}(\mathrm{OOB})$ value between the control model and the full model as a proxy. Briefly, the two models (Eqs. 1 and 2) can be defined as follows:

$$
\text { Sales }=\text { store characteristics effects }+ \text { economic effects }+ \text { temporal effects }
$$

Sales $=$ store characteristics effects + economic effects + temporal effects + weather effects

To enable validation of the random forest models, the data was initially split 70:30 into training and test datasets, respectively. After running each model on the training dataset (approximately 900,000 rows of data) and recording the resultant change in $\mathrm{r}^{2}$, each model was used to predict values for the unseen test dataset. Model performance was evaluated via a normalised root mean squared error (NMRSE) measure, using the range of values for normalisation.

Alongside $\mathrm{r}^{2}$ outputs, variable importance values, in the form of decreasing node impurity, were used to indicate where weather variables rank in relation to control model variables and PDPs were used to visualise the nature of the relationship between sales and the respective weather conditions. 


\section{Results}

The influence of different weather conditions on total daily item sales are shown in our initial model runs (Table 1). Results indicate that including weather increases the $r^{2}$ values for each of the model runs with total sales for the whole year and then broken down for each season. In general, the variables in the control model - store characteristic, economic and temporal effects - provide a high level of coverage of the variation in sales, accounting for approximately $86 \%$ of the total variance across the whole year. An additional 3.5\% variance can be explained by the respective weather model. When split by season, weather can be seen to have the greatest impact on sales in the spring and summer months, both of which show greater differences in $\mathrm{r}^{2}$ between models than for across the year. Conversely, weather in the autumn months has the lowest additional impact on sales, accounting for only an extra $2.4 \%$ of variation. In each case, the NRMSE values in Table 1 indicate very low levels of error and consistent declines in error are seen when the weather variables are included. As an absolute measure of model fit, this supports the added explanatory impact of the weather variables, as determined by the $r^{2}$ values, and importantly highlights that the models are not overfit.

With regards to variable importance rankings, Fig. 1 shows the movement of each variable in relative importance between the seasons. Store characteristic and economic effects consistently rank highest and lowest respectively, both showing little-to-no variation in ranking between the seasons. However, much more variation is seen in the temporal and weather variables. Wind is consistently ranked the most important weather variable, followed by temperature, whilst precipitation is found to be the least important weather condition. The biggest changes in rankings are seen between winter and spring months, driven predominantly by temporal effects. In the winter months, the time of year becomes more important than the time of the week and the prevailing weather conditions. It may be assumed that this is driven predominantly by the Christmas shopping season and the deviation from standard working weeks for many people as they take time off over the holiday season. Interestingly, despite being found to be the months with highest and lowest weather susceptibility, respectively, there is no change in variable ranking between summer and autumn.

Table 1 Model $\mathrm{r}^{2}$ results for total sales across England (NRMSE values for each model run shown in brackets)

\begin{tabular}{llll}
\hline Category & Control model & Weather model & Difference \\
\hline Total sales & $0.8591(0.0274)$ & $0.8942(0.0240)$ & $0.0351(-0.0034)$ \\
Spring & $0.8341(0.0309)$ & $0.8710(0.0280)$ & $0.0369(-0.0029)$ \\
$\begin{array}{l}\text { Mar - May } \\
\text { Summer }\end{array}$ & $0.8400(0.0304)$ & $0.8792(0.0272)$ & $0.0392(-0.0032)$ \\
Jun - Aug & $0.8330(0.0329)$ & $0.8574(0.0308)$ & $0.0244(-0.0021)$ \\
$\begin{array}{l}\text { Autumn } \\
\text { Sep - Nov }\end{array}$ & $0.8276(0.0312)$ & $0.8537(0.0295)$ & $0.0261(-0.0017)$ \\
$\begin{array}{l}\text { Winter } \\
\text { Dec - Feb }\end{array}$ & & & \\
\hline
\end{tabular}




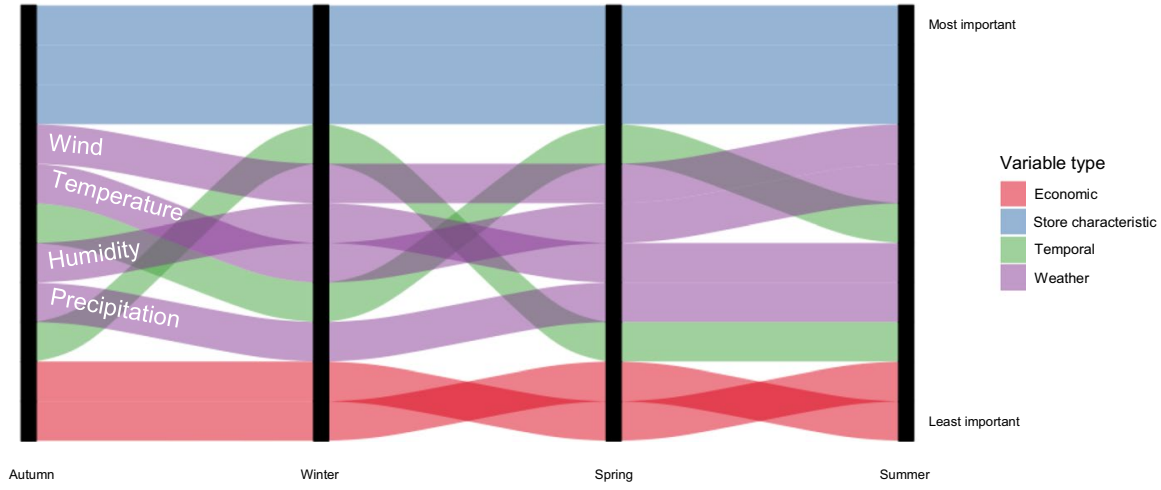

Fig. 1 Relative importance rankings of different variable types for each season

The partial dependence plots in Figs. 2, 3 show the change in total sales $(\hat{y})$ with each of the changing weather conditions and are all ordered according to their variable importance ranking. The whiskers at the base of the plot indicate the deciles for each weather condition. With respect to the total sales throughout the year, shown in Fig. 2, wind and humidity both present a predominantly negative association with sales, with respective increases both leading to a general decline in average sales. However, in both cases these trends appear to reverse in the top $10 \%$ of values with identifiable thresholds around $10 \mathrm{~m} / \mathrm{s}$ wind and $0.01 \mathrm{~kg} / \mathrm{kg}$ (or $10 \%$ ) humidity. Although presenting a highly skewed distribution of values, a similar pattern is seen between precipitation and sales. The far-left plot shows a strong negative relationship in the majority of precipitation values; however, this relationship becomes more complex in the top decile and shows signs of reversal in trend. With regards to the plot for temperature, overall the opposite relationship is seen. Up to a threshold of around $10{ }^{\circ} \mathrm{C}$, average sales appear to plateau then steadily increase with rising temperatures. Figure 3 allows the comparison of relationships between sales and weather conditions across the seasons. The most notable deviations from the whole year averages are the summer wind, autumn temperature, spring humidity and winter precipitation plots.
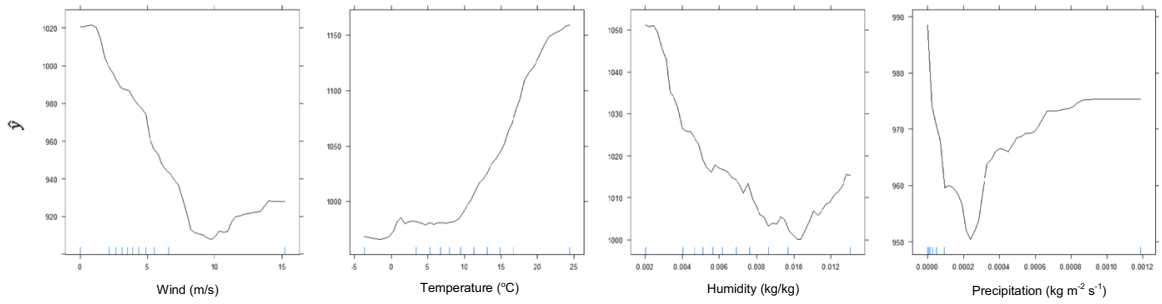

Fig. 2 Partial dependence plots for the relationship between total sales and the four weather variables in the model in order of importance ranking 

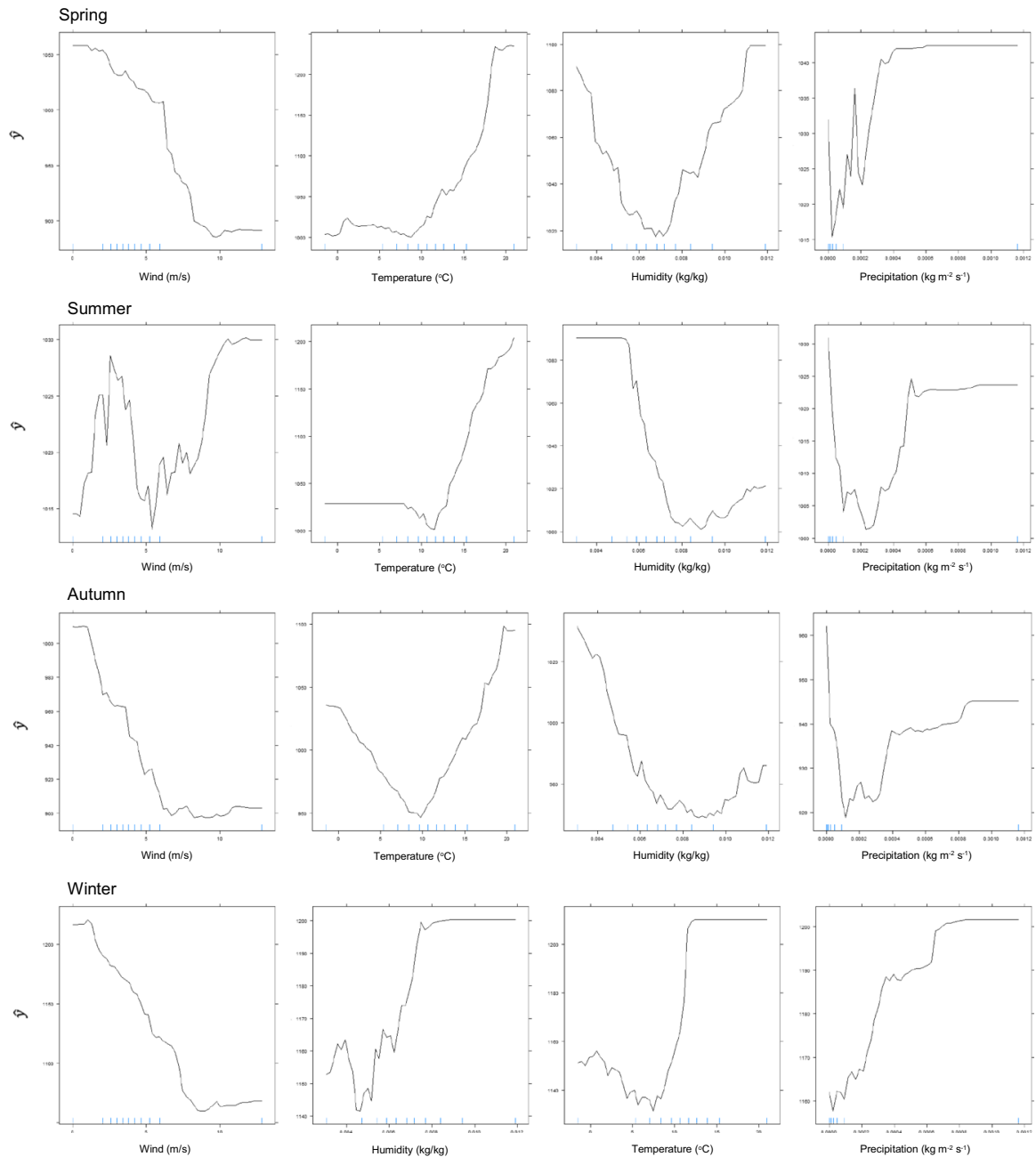

Fig. 3 Partial dependence plots for the relationship between sales and the four weather variables for each season. Ordered by variable importance ranking

\section{Weather Dependency of Product Categories}

In order to identify the top weather dependent products, in both the control and weather model, total item sales was replaced by the number of items sold in each of the 28 product categories enabling them to be ranked in terms of their weather dependency. Although available in higher resolution, this level of category was chosen in order to balance knowledge gain with modelling efficiency and avoid encountering low counts as a result of splitting the data too far.

The five product categories with the highest difference in $r^{2}$ values, and therefore considered as the most weather dependent, are identified in Table 2. The 
Table 2 Model $r^{2}$ results for the top 5 weather dependent product categories compared to the results for total sales (NRMSE values for each model run shown in brackets)

\begin{tabular}{llll}
\hline Category & Control model & Weather model & Difference \\
\hline Total sales & $0.8591(0.0274)$ & $0.8942(0.0240)$ & $+0.0352(-0.0034)$ \\
Health food & $0.8005(0.0065)$ & $0.8646(0.0053)$ & $+0.0641(-0.0012)$ \\
Heart health \& dental & $0.8335(0.0277)$ & $0.8837(0.0234)$ & $+0.0502(-0.0043)$ \\
Personal care items & $0.8275(0.0236)$ & $0.8762(0.0201)$ & $+0.0487(-0.0034)$ \\
Cosmetic fashion brands & $0.6959(0.0160)$ & $0.7445(0.0148)$ & $+0.0486(-0.0011)$ \\
Winter medicines & $0.8147(0.0257)$ & $0.8615(0.0224)$ & $+0.0468(-0.0033)$ \\
\hline
\end{tabular}

results for total sales are also shown here as a comparison and again, NRMSE values for each model run are indicated below in brackets. The health food category appears as the most weather dependent category with an additional $6.41 \%$ variance explained when the weather variables are included. This is followed by heart health \& dental, personal care items, cosmetic fashion brands and winter medicines with increases of between $5.02 \%$ and $4.68 \%$ in variance explained. Importantly, all models show very small error values that consistently decline between the two model runs. Of the five categories shown, cosmetic fashion brands is the only category with $\mathrm{r}^{2}$ values less than $80 \%$, indicating that the variables in the model are not able to explain the variation in these sales as well as the other products. Despite this, the category has among the lowest levels of predictive error.

Figure 4 presents the weather partial dependence plots for the top five categories, again each ordered according to their respective variable importance ranking. Temperature and wind alternate as the most important weather variables on their sales variance, with humidity and precipitation consistently ranking third and fourth, respectively. With regards to the trends between weather and sales, there are a huge range observed with no one weather condition presenting a consistent pattern of influence across each of the different product categories. Common across almost all categories, the highest sales are associated with the lowest wind and humidity values, however each show varying trends of reversal or plateau at different thresholds. Another notable relationship is that seen between temperature and sales. For the top 4 categories the association between the two variables alternates between positive in nature and a $\mathrm{u}$-shaped graph. In all cases, the warmest temperatures correspond to the highest average sales, however for health food and cosmetic fashion brands, lower temperatures also correspond to high sales. For the winter medicines category, this relationship between temperature and sales is far more complex with lowest sales corresponding to temperatures below $0{ }^{\circ} \mathrm{C}$ and also in the mid-ranges. The highly skewed distribution makes the varying effects of precipitation on sales difficult to see, but in most cases the precipitation graphs look similar to the one seen for total sales in Fig. 2. 

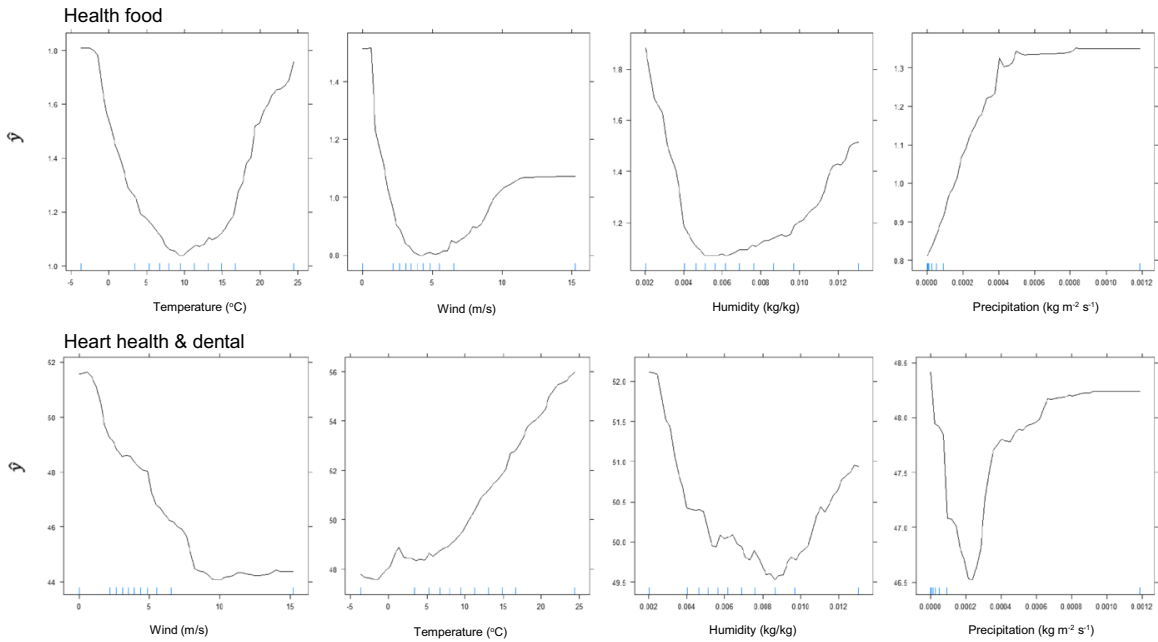

Personal care items


Cosmetic fashion brands


Fig. 4 Partial dependence plots for the relationship between sales and the four weather variables for each of the top 5 weather dependent product categories. Ordered by variable importance ranking 


\section{High Street vs Out-of-town Retail Centre Sales}

For the purpose of examining the local spatial variations, the sales data was subset according to the location of the store where each sale took place. This enabled a comparison between the influence of weather on high street and out-of-town purchasing. In this instance the sales outcome once again refers to total number of items sold across all categories and stores located outside of these traditional centres (e.g. in transport hubs) were not included.

It can be seen from Table 3 that the variables in the control model are able to explain the variance in high street sales substantially better than the sales in out-of-town stores, with an $\mathrm{r}^{2}$ value of approximately $80 \%$ compared to $62 \%$, respectively. In addition, it is apparent that the weather conditions have a greater influence on high street sales, with an additional 5.5\% variance explained once the weather variables are included compared to less than $1 \%$ in out-of-town sales. Again, in both instances the level of error decreases between each model run.

When the relationships between weather and sales are displayed in the partial dependence plots in Fig. 5, large disparities between the two locations appear. The plots for high street stores are notably similar to those for total sales in Fig. 2 but the relationships for out-of-town sales present far more complex relationships with each of the weather conditions, particularly wind and temperature. With respect to out-of-town store sales, an overall positive association is seen with the highest values of wind and for temperature, there are sales peaks at both high and low temperatures with lower sales in the mid-ranges. Both of these trends differ significantly from what was seen previously and from what is seen for high street stores.

\section{Regional Variation}

To explore any regional differences in weather influence, the sales data was subset into the nine statistical regions across England and, all stores were included. Regional level analysis enables geographical variations to be explored whilst maintaining large amounts of data within each subset to be used for analysis.

The model results in Table 4 indicate that sales in London can be clearly considered to be the most weather dependent across England with an increase in $r^{2}$ of $3.6 \%$, followed by the South East and the West Midlands, both with increases

Table 3 Model $\mathrm{r}^{2}$ results for sales from both high street and out-of-town stores compared to sales across all stores (NRMSE values for each model run shown in brackets)

\begin{tabular}{llll}
\hline Store type & Control model & Weather model & Difference \\
\hline Total sales & $0.8591(0.0274)$ & $0.8942(0.0240)$ & $+0.0352(-0.0034)$ \\
High street stores & $0.7990(0.0209)$ & $0.8536(0.0182)$ & $+0.0546(-0.0027)$ \\
Out-of-town stores & $0.6230(0.0205)$ & $0.6324(0.0173)$ & $+0.0094(-0.0032)$ \\
\hline
\end{tabular}



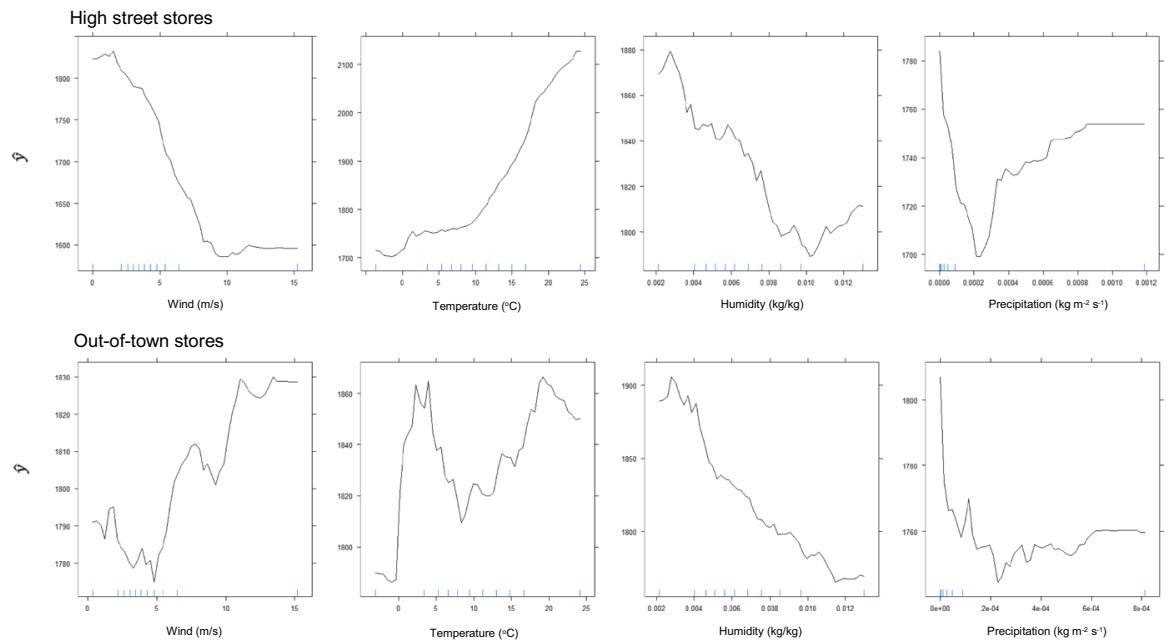

Fig. 5 Partial dependence plots for the relationship between sales and the four weather variables for each store location. Ordered by variable importance ranking

of $2-2.1 \%$. The region with the least weather dependent sales appears to be Yorkshire and the Humber with less than $1 \%$ difference in $\mathrm{r}^{2}$ values between the two models. These results, classified by natural breaks (Jenks) optimisation, are shown on the map of England in Fig. 6. It is clear that sales in London experience a significantly greater level of influence from weather than the rest of the country. Conversely, areas with the lowest susceptibility to weather influence appear to be the South West and North Eastern regions of England, which are both the most geographically 'exposed' regions to adverse weather conditions (e.g. coastal winds, increased precipitation, lower temperatures) and of predominantly rural composition.

Table 4 Model $r^{2}$ results for total sales in each region compared to the results for the whole country (NRMSE values for each model run shown in brackets)

\begin{tabular}{llll}
\hline Region & Control model & Weather model & Difference \\
\hline Total sales & $0.8591(0.0274)$ & $0.8942(0.0240)$ & $+0.0352(-0.0034)$ \\
London & $0.8931(0.0320)$ & $0.9292(0.0264)$ & $+0.0361(-0.0056)$ \\
South East & $0.9294(0.0205)$ & $0.9502(0.0173)$ & $+0.0208(-0.0032)$ \\
West Midlands & $0.9100(0.0341)$ & $0.9300(0.0298)$ & $+0.0200(-0.0043)$ \\
East of England & $0.9361(0.0271)$ & $0.9526(0.0237)$ & $+0.0165(-0.0034)$ \\
North West & $0.9484(0.0172)$ & $0.9629(0.0147)$ & $+0.0146(-0.0025)$ \\
East Midlands & $0.9367(0.0279)$ & $0.9509(0.0240)$ & $+0.0142(-0.0038)$ \\
South West & $0.9480(0.0209)$ & $0.9598(0.0182)$ & $+0.0118(-0.0027)$ \\
North East & $0.9549(0.0144)$ & $0.9661(0.0120)$ & $+0.0112(-0.0023)$ \\
Yorkshire and the Humber & $0.9535(0.0204)$ & $0.9622(0.0182)$ & $+0.0086(-0.0022)$ \\
\hline
\end{tabular}


Fig. 6 Regional differences in weather influence on total sales


\section{Discussion}

This study provides empirical evidence that weather conditions have a measurable impact on retail sales. However, it is also evident that other variables included in the model make up a larger proportion of the explainable variance, with store characteristics having consistently the most important role. When looking at overall item sales counts, our findings show an extra $3.5 \%$ of variance explained when the weather variables are added into the model. The results are comparable to those of both Badorf and Hoberg (2020) and Arunraj and Ahrens (2016), who with their respective models and a similar methodology were able to explain between 4 and $6 \%$ extra variance with added weather variables. In both of these cases however, the control models were able to explain much less of the variance than seen here.

The results predominently follow intuitive patterns of more favourable weather (e.g. higher temperatures) increasing sales whilst less favouable conditions leading to an overall decrease. In agreement with Steele (1951), this is likely to be a result of these less favourable conditions, such as higher wind speeds, precipitation and humidity, either dissauding or physically preventing consumers from visiting retail outlets.

The significance of temperature found by our study, to an extent, supports other studies that have frequently identified temperature as a key influence on sales (e.g. Bahng \& Kincade, 2012; Murray et al., 2010; Ramanathan \& Muyldermans, 2010). A somewhat less clear picture emerges in the case of precipitation, with some previous studies having supported the results presented here and finding it the least 
important weather variable (e.g. Bahng \& Kincade, 2012). Although this contradicts some other findings (e.g. Linden (1959); Parsons (2001) or Arunraj and Ahrens (2016)) ranking precipitation amongst the most influential variables, all these studies were based outside of the UK where typically the weather is sunnier and drier. Also humidity, - a not often considered factor when analysising sales purchases, - has been found to have a significant, but not strong, influence supporting the findings of Aultmann-Hall et al. (2009) and Arunraj and Ahrens (2016). Finally, wind speed, found by our study as the most influential weather variable on sales, has seldom been incorpotaed into previous studies. Rare examples of inclusion of this variable have found the impacts insignifcant in other locations (e.g. Aultmann-Hall et al., 2009), however the UK has been regularly cited as one of the windiest places in Europe (e.g. Burgess, 2017) and the level of influence seen here may be a reflection of this.

Seasonal Patterns/variations An interesting picture emerges in terms of seasonal variation with the highest levels of weather influence found in the summer and spring months, respectively, and lowest in the autumn months. High levels of influence in the spring are supported by both Badorf and Hoberg (2020) and Bertrand et al., (2015), who found the strongest weather influences in these months for their respective retail sector sales, with the latter also finding the weakest influence in the autumn months. Although interactions between weather conditions have not been explicitly studied here, consideration of these impacts and their seasonality may help to understand the notable deviations seen in the associations between weather conditions and sales. Two particular examples of this are seen in the summer wind and winter precipitation plot. It is known that both wind and humidity can significantly influence the perception of temperature (Höppe, 1999). As a result, when summer temperatures are particularly high, and subsequently produce uncomfortable shopping conditions, increased wind-chill may act to make conditions more bearable. Conversely, in winter when temperatures are overall much colder, the presence of rain and associated higher humidity levels can help to create warmer perceived temperatures.

Weather Dependent Product Categories As expected, the magnitude of weather impact seen here differs considerably between product type. Although pertaining only to the products sold by this particular retailer and therefore not universally representative, all product categories included in this analysis showed some degree of day-to-day weather sensitivity. The top five weather dependent categories identified represented a diverse range of products indicating that no one distinct classification of product, e.g. food and drink or cosmetics, is dominantly weather dependent. For retailers, an understanding of how weather influences the sales of individual products is paramount for operational planning across the board. The insights presented by this study can be used to inform aspects such as supply chain planning, stock management, promotional activities and targeted marketing campaigns. By making these processes more efficient, businesses can make themselves more sustainable through the reduction of waste and economic losses (Starr-McCleur, 2000; NRF, 2018). 
The lack of consistency in the associations between each weather condition and the different product categories found in this study reiterates the diversity across the categories identified and complexity behind these relationships. Due to the nature of the products sold by this particular retailer, three supergroups into which these product categories fall can be derived: (1) essential, immediate items e.g. winter medicines; (2) essential, non-immediate items e.g. heart health \& dental and personal care items; and (3) non-essential items e.g. health food and cosmetics. When considered in terms of these supergroups, distinctions and groupings between the nature of associations can be identified. This is perhaps clearest in terms of temperature or precipitation dependency, with essential, non-immediate items showing associations similar to those for total sales, whereas non-essential items differ significantly. Winter medicines, however, show a much more complex association between sales and temperature in particular. One explanation for this considerable deviation is the inherent relationship between the product and colder weather. Further to this, sales of medicines are often dependent on whether purchase is preparatory or in direct response to a medical need (Davies et al., 2018). In the instance of a medical need, they become immediately essential purchases where there may be little consideration of the prevailing weather conditions.

\section{Store Location Implications and Spatial Patterns}

Local spatial variation in weather influence, studied as a comparison between the sales of high street and out-of-town stores perhaps unsurprisingly, shows that high street sales are significantly more weather dependent than the out-of-town equivalent. High street stores tend to be far more exposed to prevailing weather conditions due to lack of cover and detached parking facilities (Badorf \& Hoberg, 2020) and, as such, sales in these environments are more susceptible to weather influence. This finding is supported in a report by WeatherAds (2015) who state that high street stores are often worst impacted by inclement weather whilst indoor shopping centres can often see an increase in footfall and subsequently sales. Nevertheless, the weak relationship for out-of-town sales highlights the added complexity behind consumer decision making processes and suggests that in this case there are other significant factors at play that have not been accounted for in our model. This complexity is further reflected in the nature of the associations seen between the weather conditions and out-of-town sales. Deviating from those seen for total sales, some of these associations are likely to be attributable to close parking availability or air-conditioned shopping centres, effectively removing some of the obstacles of less favourable weather conditions.

In terms of the regional variations, the more significant impact of weather conditions on daily sales in Greater London may indicate a more complex retail environment in London than in other regions. Factors such as the prevalence of tourists (Maxim, 2016) or commuters adding to the daytime population of the region may alter retail demand and performance (Berry et al., 2016). Although no directly comparable research is available, where other retail-based trends in England have been studied, London is often found to show either opposing trends to other regions or more extreme 
values (e.g. Grimsey, 2018; Portas, 2011; Rhodes, 2018). In addition, the patterns of highest weather influence appear to correspond with the warmest and driest regions of the country, whilst lowest levels correspond to regions notorious for the coldest or windiest weather, potentially indicating associations between weather resilience and level of influence. The patterns may also be indicative of urban-rural differences and this has subsequent impacts on variations in store catchment size. For example, at a crude level, larger distances to a store in rural areas are likely to result in greater car usage and therefore less exposure to prevailing weather conditions. Although this paper offers not enough evidence to test these theories, there are clear benefits of better spatial understanding of the variable weather impact. These new insights can lead to more efficient and adaptable stock supply for different store types and regions, as well as the management of staffing resource (NRF, 2018), ensuring efficient distribution. As such, we believe this warrants future research developments in the area.

\section{Conclusion}

Daily weather conditions play an important role in influencing consumer purchasing behaviours, both for overall item sales and individual product categories, as well as at varying spatial scales. These fluctuations in response to prevailing weather conditions have subsequent impacts on factors across the business such as supply chains, stock management and marketing practices. An increased understanding of the associations present between weather and sales provides insight for retailers to negotiate these factors effectively and maintain a more sustainable business.

Using a machine learning analysis this paper has made an attempt to quantify the level of influence experienced for aggregate and stratified sales, as well as explore the nature of this influence, including the local and regional variations. Fundamentally, we have shown that, although store characteristics are consistently greater predictors, weather does have a measurable influence on the sales counts of individual items, and one which shows notable seasonal deviations. Overall, and perhaps expectedly, item sales tend to show a positive association with more favourable weather conditions and negative tendencies with less favourable conditions. When stratified by product category, larger variations in influence levels are evident and no one distinct product type dominates amongst the top five weather dependent categories. From visualising the nature of associations between sales and weather conditions, three super-groups of categories were identified based on level of necessity rather than the product itself. With respect to spatial variations, significant differences were found in the level of weather influence between high street and out-of-town store sales, and the regional differences demonstrated potential connections to commuting behaviours and weather resilience.

Primarily, the implications of these findings can lead to more comprehensive understanding of the factors that drive retail sales. The additional explanatory power of the weather variables included here indicates that sales predictions would benefit from considering these conditions. Broken down by season, product category and store location, it is clear how the level of influence differs with these factors and this information can be used by interested groups accordingly. One major strength of this 
research is the coverage and depth of data available. This has enabled valuable insights to be drawn that add to existing research, predominantly based in mainland Europe and the US, as well as addressing the dearth of research available for the UK. These insights can be used to optimise supply and stock management for different products and store types; tailor promotional and marketing activity; and effectively organise staffing resource. Furthermore, by removing weather volatility from sales figures, errors in year-on-year projections can be minimised (NRF, 2018). Additionally, we argue that huge value can be gained from novel insights into regional variations, particularly for retailers that have a wide-spread presence nationally or even multi-nationally.

Although the study has been rigorously designed, there are some limitations that are inherent to such examination. It has already been recognised that this analysis pertains to a specific retailer and the products they hold so cannot be considered wholly representative of the UK retail sector Additionally, it has not been possible to consider product pricing or price promotional activities that may be influential in consumer purchasing behaviours. Promotions, in particular, may incite more unplanned or spontaneous purchasing decisions (Kiran et al., 2012) that are arguably significantly less likely to be made with consideration of the prevailing weather conditions. Additionally, there is information to be gained from looking at the interrelation of weather variables and the subsequent impact on item sales, however this was not explicitly possible within the methodology used in this study.

Addressing the dearth of developments in this research area, for which it is hoped that this study will be a forerunner, could focus on different retail sectors and a larger range of retailers or the specific products they sell. Further to this, for retailers with multi-channel purchasing options, research could examine the extent to which channel substitution happens in response to different weather conditions or loyalty card data could be used to investigate patterns across different demographic groups. There is also huge scope for more spatially based retail research, taking into account different types of retail centres beyond what was achieved in this paper and smallerscale regional studies. Although not often widely available for researchers, the data used here is not dissimilar to that held by many different retailers. Therefore, there is large potential for the extension of this kind of research, both for brick-and-mortar retailers and those with an online presence.

Acknowledgements The authors would like to acknowledge the Consumer Data Research Centre (CDRC) who provided the data, secure lab facilities and administrative support.

Funding CDRC (ES/L011840/1), CDT (ES/P000401/1).

Data Availability Available through Consumer Data Research Centre.

Open Access This article is licensed under a Creative Commons Attribution 4.0 International License, which permits use, sharing, adaptation, distribution and reproduction in any medium or format, as long as you give appropriate credit to the original author(s) and the source, provide a link to the Creative Commons licence, and indicate if changes were made. The images or other third party material in this article are included in the article's Creative Commons licence, unless indicated otherwise in a credit line to the material. If material is not included in the article's Creative Commons licence and your intended use is not permitted by statutory regulation or exceeds the permitted use, you will need to obtain permission directly from the copyright holder. To view a copy of this licence, visit http://creativecommons.org/licen ses/by/4.0/. 


\section{References}

Agnew, M., \& Thornes, J. (1995). The weather sensitivity of the UK food retail and distribution industry. Meteorological Applications, 2, 137-147.

Allenby, G., Jen, L., \& Leone, R. (2012). Economic trends and being trendy: The influence of consumer confidence on retail fashion sales. Journal of Business \& Economic Statistics, 14(1), 103-111.

Alzubaidi, H., Vignali, C., Davies, B., \& Schmidt, R. (1997). Town centre versus out-of-town shopping: A consumer perspective. International Journal of Retail \& Distribution Management, 25(2), 78-89. https://doi.org/10.1108/09590559710160373.

Arunraj, N., \& Ahrens, D. (2016). Estimation of non-catastrophic weather impacts for retail industry. International Journal for Retail \& Distribution Management, 44(7), 731-753. https://doi.org/10. 1108/IJRDM-07-2015-0101.

Astbury, G., \& Thurstain-Goodwin, M. (2014). Measuring the impact of out-of-town retail development on town centre retail property in england and wales. Applied Spatial Analysis and Policy, 7, 301-316.

Attaset, V., Schneider, R., Arnold, L. \& Ragland, D. (2010). Effects of weather variables on pedestrian volumes in Alameda County, California. Presented at the 89th Annual Meeting of the Transport Research Board, Washington, D.C. 10-14 January 2010.

Aultman-Hall, L., Lane, D. \& Lambert, R. (2009). Assessing the Impact of Weather and Season on Pedestrian Traffic (09-2765). Presented at the 88th Annual Meeting of the Transportation Research Board, Washington, D.C. 11-15 January 2009. Badof, F. \& Hoberg, K 2020 The impact of daily weather on retail slaes: An empirical stufy in brick-and-mortar stores. Journal of Retailing and Consumer Services. https://doi.org/10.1016/j.jretconser.2019.101921

Aye, G. C., Balcilar, M., Gupta, R., \& Majumdar, A. (2015). Forecasting aggregate retail sales: The case of South Africa. International Journal of Production Economics, 160, 66-79. https://doi.org/10. 1016/j.ijpe.2014.09.033

Badorf, F., \& Hoberg, K. (2020). The impact of daily weather on retail sales: An empirical study in brick-and-mortar stores. Journal of Retailing and Consumer Services, 52, 101921. https://doi.org/ 10.1016/j.jretconser.2019.101921

Bahng, Y., \& Kincade, D. (2012). The relationship between temperature and sales: Sales data analysis of a retailer of branded women's business wear. International Journal of Retail \& Distribution Management, 40(6), 410-426. https://doi.org/10.1108/09590551211230232.

Beheshti-Kashi, S., Karimi, H. R., Thoben, K. D., Lütjen, M., \& Teucke, M. (2015). A survey on retail sales forecasting and prediction in fashion markets. Systems Science \& Control Engineering, 3(1), 154-161. https://doi.org/10.1080/21642583.2014.999389

Berry, T., Newing, A., Davies, D., \& Branch, K. (2016). Using workplace population statistics to understand retail store performance. The International Review of Retail, Distribution and Consumer Research, 26(4), 375-395. https://doi.org/10.1080/09593969.2016.1170066.

Bertrand, J. L., Brusset, X., \& Fortin, M. (2015). Assessing and hedging the cost of unseasonal weather: Case of the apparel sector. European Journal of Operational Research, 244(1), 261-276. https://doi. org/10.1016/j.ejor.2015.01.012

Bradlow, E. T., Gangwar, M., Kopalle, P., \& Voleti, S. (2017). The role of big data and predictive analytics in retailing. Journal of Retailing, 93(1), 79-95. https://doi.org/10.1016/j.jretai.2016.12.004

Breiman, L. (2001). Random Forests. Machine Learning, 45, 5-32.

British Retail Consortium. (2020). The latest movements in retail employment. http://brc.org.uk/media/ 673737/employment.pdf

Burgess, P. (2017). Agroforestry in the UK. Quarterly Journal of Forestry, 111(2), 111-116.

Chu, B. (2018). 'Beast from the East' responsible for biggest drop in UK retail sales in a year. https:// www.independent.co.uk/news/business/news/uk-retail-sales-latest-beast-east-biggest-drop-thirdquarter-ons-a8311756.html

Coca-Stefaniak, A. (2013). Successful town centres: Developing effective strategies. Technical Report. Association of Town and City Management, London, UK.

Davies, A., Green, M., \& Singleton, A. (2018). Using machine learning to investigate self-medication purchasing in England via high street retailer loyalty card data. PLoS One, 13(11), e0207523. https://doi.org/10.1371/journal.pone.0207523. 
Dellaert, B., Arentze, T., \& Timmermans, H. (2008). Shopping context and consumers' mental representation of complex shopping trip decision problems. Journal of Retailing, 84(2), 219-232. https://doi. org/10.1016/j.jretai.2008.02.001.

Divakar, S., Ratchford, B., \& Shankar, V. (2005). CHAN4CAST: A multichannel, multiregion sales forecasting model and decision support system for consumer packaged goods. Marketing Science, 24(3), 334-350. https://doi.org/10.1287/mksc.1050.0135

Dolega, L. \& Celińska-Janowicz, D. (2015). Retail resilience: A theoretical framework for understanding town centre dynamics. Studia Regionalne i Lokalne - Polish Sect. Regional Studies Associatio, 2(60), 9-31.

Ellithorpe, D., \& Putnam, S. (2000). Weather derivatives and their implications for power markets. The Journal of Risk Finance, 1(2), 19-28.

Fildes, R., Ma, S., \& Kolassa, S. (2019). Retail forecasting: Research and practice. International Journal of Forecasting. https://doi.org/10.1016/j.ijforecast.2019.06.004

Gorter, C., Nijkamp, P., \& Klamer, P. (2003). The Attraction Force of Out-of-Town Shopping Malls: A case Study on Run-Fun Shopping in the Netherlands. Tijdschrift Voor Economische En Sociale Geografie, 94(2), 219-229. https://doi.org/10.1111/1467-9663.00250.

Graham, C. (2017). Footfall, attraction and conversion; a retail empirical generalisation. Conference Paper. London South Bank University.

Greenwell, B. (2017). pdp: An R Package for Constructing Partial Dependence Plots. The R Journal, 9(1), 1-16.

Grewal, D., Roggeveen, A., \& Nordfält, J. (2017). The future of retailing. Journal of Retailing, 83(1), 1-6. https://doi.org/10.1016/j.jretai.2016.12.008.

Grimsey, B. (2018). The Grimsey Review 2.

Hanna, E., Hall, R., \& Overland, J. (2017). Can Arctic warming influence UK extreme weather? Weather, 72(11), 346-352. https://doi.org/10.1002/wea.2981

Herrera, M., Ferreira, A., Coley, D., \& de Aquino, R. (2016). SAX-quantile based multiresolution approach for finding heatwave events in summer temperature time series. AI Communications, 29, 725-732.

Höppe, P. (1999). The physiological equivalent temperature - a universal index for the biometeorological assessment of the thermal environment. International Journal of Biometeorology, 43, 71-75.

Howard, E. (2007). New shopping centres: Is leisure the answer? Int. Journal of Retail \& Distribution Management, 35(8), 661-672. https://doi.org/10.1108/09590550710758649.

Inman, P. (2018). UK heatwave and World Cup boost retail sales. https://www.theguardian.com/business/ 2018/aug/16/sunshine-and-football-give-uk-retail-sales-unexpected-boost

Jang, S. (2004). Mitigating tourism seasonality: A quantitative approach. Annals of Tourism Research, 31(4), 819-836. https://doi.org/10.1016/j.annals.2004.02.007.

Jeong, J., Resop, J., Mueller, N., Fleisher, D., Yun, K., Butler, E., et al. (2016). Random forests for global and regional crop yield predictions. PLoS One, 11(6), e0156571. https://doi.org/10.1371/journal. pone.0156571.

Jones, C., \& Livingstone, N. (2017). The 'online high street' or the high street online? The implications for the urban retail hierarchy. The International Review of Retail, Distribution and Consumer Research, 28(1), 47-63. https://doi.org/10.1080/09593969.2017.1393441.

Kantamaneni, K., \& Du, X. (2017). Is catastrophic climate change turning Britain into a hurricane hotspot? International Journal of Environmental Research, 11(5-6), 569-578.

Kiran, V., Majumdar, M., \& Kishore, K. (2012). Innovation in in-store promotions: Effects on consumer purchase decision. European Journal of Business and Management, 4(9), 36-44.

Knoeferle, K., Paus, V., \& Vossen, A. (2017). An upbeat crowd: Fast in-store music alleviated negative effects of high social density on customers' spending. Journal of Retailing, 93(4), 541-549. https:// doi.org/10.1016/j.jretai.2017.06.004.

Lang, Å. (2012). City retailers' perceptions of competition: A choice experiment. HUI Working Papers 58.

Lazo, J., Lawson, M., Larsen, P., \& Waldman, D. (2011). U.S. Economic sensitivity to weather variability. Bulletin of the American Meteorological Society, 92, 709-720. https://doi.org/10.1175/2011BAMS2928.1.

Linden, F. (1959). The business of department stores. Technical report.

Lusch, R., Serpkenci, R. \& Orvis, B. (2015). Determinants of Retail Store Performance: A Partial Examination of Selected Elements of Retailer Conduct. In: Grant K., Walker I. (eds) Proceedings of the 1995 World Marketing Congress. Developments in Marketing Science: Proceedings of the Academy of Marketing Science. Springer, Cham.

Makkar, G. (2020). Real-time footfall prediction using weather data: A case on retail analytics. In: Sharma N., Chakrabarti A. \& Balas V. (eds). Data Management, Analytics and Innovation. 
Advances in Intelligent Systems and Computing, vol 1042. Springer, Singapore. https://doi.org/10. 1007/978-981-32-9949-8_37

Martinez-de-Albeniz, V. \& Belkaid, A. (2019). Here comes the sun: Fashion goods retailing under weather shocks. Working paper.

Maxim, C. (2016). Sustainable tourism implementation in urban areas: A case study of London. Journal of Sustainable Tourism, 24(7), 971-989. https://doi.org/10.1080/09669582.2015.1115511.

Meltzer, R. (2016). Retail churn can bring both volatility and vitality to a neighbourhood. USAPP American Politics and Policy Blog (10 Dec 2016).

Mirasgedis, S., Georgopoulou, E., Sarafidis, Y., Papagiannaki, K., \& Lalas, D. (2014). The impact of climate change on the pattern of demand for bottled water and non-alcoholic beverages. Business Strategy and the Environment, 23(4), 272-288. https://doi.org/10.1002/bse.1782

Murphy, J., Sexton, D., Jenkins, G., Boorman, P., Booth, B., Brown, K., Clark, R., Collins, M., Harris, G. \& Kendon, L. (2010). UK Climate projections science report: Climate change projections. Exeter, Met Office Hadley Centre.

Murray, K., Di Mur, F., Finn, A., \& Leszczyc, P. (2010). The effect of weather on consumer spending. Journal of Retailing and Consumer Services, 17(6), 512-520. https://doi.org/10.1016/j.jretconser. 2010.08.006.

National Retail Federation. (2018). 5 myths about weather and it's impact on retail. https://nrf.com/sites/ default/files/2018-10/Weather\%20Myths\%20Report.pdf

Newing, A., Clarke, G., \& Clarke, M. (2018). Applied spatial modelling for retail planning in tourist resorts. International Journal of Retail \& Distribution Management, 46(11), 1117-1132. https://doi. org/10.1108/IJRDM-10-2017-0253.

Office for National Statistics (2014). Economic review - December 2013. http://www.ons.gov.uk/ons/ dcp171766_343680.pdf

Padilla, A., Hermosilla, A., \& Ozores, O. (2017). The impact of out-of-town shopping centres on towncentre retailers and employment: The case of the Region of Murcia. Land Use Policy, 65, 277-286. https://doi.org/10.1016/j.landusepol.2017.04.014

Parker, C., Ntounis, N., Quin, S. \& Grime, I. (2014). High Street research agenda: identifying High Street research priorities. Journal of Place Management and Development, 7(2), 176-184. https://doi.org/ 10.1108/JPMD-06-2014-0008

Parker, C., Ntounis, N. Quin, S. \& Millington, S. (2015). High Street UK 2020 Project report: Identifying factors that influence vitality and viability.

Parsons, A. (2001). The association between daily weather and daily shopping patterns. Australasian Marketing Journal, 9(2), 78-84.

Parnaudeau, M., \& Bertrand, J. (2018). The contribution of weather variability to economic sectors. Applied Economics, 50(43), 4632-4649. https://doi.org/10.1080/00036846.2018.1458200.

Pendall, R., Foster, K., \& Cowell, M. (2010). Resilience and regions: Building understanding of the metaphor. Cambridge Journal of Regions, Economy and Society, 3(1), 71-84. https://doi.org/10.1093/ cjres/rsp028.

Portas, M. (2011). The Portas Review: The future of our high streets.

Ramanathan, U., \& Muyldermans, L. (2010). Identifying demand factors for promotional planning and forecasting: A case of a soft drink company in the UK. International Journal of Production Economics, 128(2), 538-545. https://doi.org/10.1016/j.ijpe.2010.07.007.

Retail Economics. (2020). UK retail stats and facts. https://www.retaileconomics.co.uk/libra ry-retail-stats-and-facts

Rhodes, C. (2018). Retail sector in the UK. House of Commons Library.

Robinson, E., Blyth, E., Clark, D., Comyn-Platt, E., Finch, J. \& Rudd, A. (2017). Climate hydrology and ecology research support system meteorology dataset for Great Britain (1961-2015) [CHESS-met] v1.2. NERC Environmental Information Data Centre. https://doi.org/10.5285/b745e7b1-626c-4ccc-ac27-56582e77b900

Singleton, A., Dolega, L., Riddlesden, D., \& Longley, P. (2015). Measuring the spatial vulnerability of retail centres to online consumption through a framework of e-resilience. Geoforum, 69, 5-18. https://doi.org/10.1016/j.geoforum.2015.11.013

Sivillo, J. \& Reilly, D. (2004). Forecasting consumer product demand with weather information: A case study. The Journal of Business Forecasting Methods \& Systems.

Slingo, J., Belcher, S., Scaife, A., McCarthy, M., Saulter, A., McBeath, K., Jenkins, A., Huntingford, C., Marsh, T., Hannaford, J. \& Parry, S. (2014). The recent storms and floods in the UK. Exeter, UK Met Office.

Starr-McCluer, M. (2000). The effects of weather on retail sales. Federal Reserve Board of Governors. 
Steele, A. (1951). Weather's effect on the sales of a department store. The Journal of Marketing, 15(4), 436-443.

Stulec, I. (2013). On weather sensitivity in retail industry. International Journal of Retail Management and Research, 3(3), 1-10.

Stulec, I., Petljak, K., \& Naletina, D. (2019). Weather impact on retail sales: How can weather derivatives help with adverse weather deviations? Journal of Retailing and Consumer Services, 49, 1-10. https://doi.org/10.1016/j.jretconser.2019.02.025.

Sturley, C., Newing, A., \& Heppenstall, A. (2017). Evaluating the potential of agent-based modelling to capture grocery retail store choice behaviours. The International Review of Retail, Distribution and Consumer Research, 28(1), 27-46. https://doi.org/10.1080/09593969.2017.1397046.

Subak, S., Palutikof, J., Agnew, M., Watson, S., Bentham, C., Cannell, M., et al. (2000). The impact of the anomalous weather of 1995 on the UK economy. Climatic Change, 44, 1-26.

Tartaglione, A., Bruni, R., \& Bozic, M. (2019). Exploring the retail industry environment using nonlinear analysis. International Journal of Retail \& Distribution Management, 47(4), 453-470. https://doi. org/10.1108/IJRDM-09-2017-0224.

Theodoridis, C., Ntounis, N., \& Pal, J. (2017). How to reinvent the High Street: Evidence from the HS2020. Journal of Place Management and Development, 10(4), 380-391.

Thompson, V., Dunstone, N., Scaife, A., Smith, D., Slingo, J., Brown, S., \& Belcher, S. (2017). High risk of unprecedented UK rainfall in the current climate. Nature Communications, 8, 107.

WeatherAds. (2015). The impact of weather on retail sector in the UK. http://www.weatherads.io/blog/ 2015/august/the-impact-of-weather-on-retail-sector-in-the-uk

Wood, Z. (2019). Boxing Day sales dip blamed on poor weather and Black Friday. https://www.theguardian.com/business/2019/dec/26/boxing-day-footfall-dip-blamed-on-poor-weather-and-black-friday

Wright, M. (2020). Package 'ranger'. R package version 0.12.1. https://cran.r-project.org/web/packages/ ranger/ranger.pdf

Wright, M. \& Ziegler, A. (2017). ranger: A fast implementation of random forests for high dimensional data in C++ and R. Journal of Statistical Software, 77(1). https://doi.org/10.18637/jss.v077.i01

Wrigley, N. \& Lambiri, D. (2015). British High Streets: from Crisis to Recovery? A Comprehensive Review of the Evidence Project Report. University of Southampton, Southampton, UK.

Xia, M. \& Wong, W. (2014). A seasonal discrete grey forecasting model for fasion retailing. KnowledgeBased Systems, 57, 119-126. https://doi.org/10.1016/j.knosys.2013.12.014

Zhang, D., Zhu, P., \& Ye, Y. (2016). The effects of E-commerce on the demand for commercial real estate. Cities, 51, 106-120. https://doi.org/10.1016/j.cities.2015.11.012.

Publisher's Note Springer Nature remains neutral with regard to jurisdictional claims in published maps and institutional affiliations. 